\title{
On Foreigner Talk
}

\author{
Ruzanna Arakelyan \\ Yerevan State University
}

$\mathrm{C}$ ommunication is a vital part of human existence. It is generally accepted that the best way to preserve or create a free society which guarantees its members' rights and privileges is to learn to communicate effectively both in public and in private. Admittedly communication is a buzzword for our time. Still, communicative skill is not something we are born with. There are a lot of people who fail to communicate their needs, opinions and ideas to others even in their native language. But it is never late to learn: effective communication, either in mother tongue or in a foreign language, is a skill, which can be acquired.

Studies have shown that native speakers modify their speech when addressing nonnative speakers. However, such modifications do not always occur. Native speakers can vary the extent of their modifications within a single conversation, reflecting their changing perception of what the non-native speakers will vary in their ability to engage in foreigner talk (FT) depending on their communicative style or skills and their prior experience of communicating with non-native speakers.

FT appears to exist in most cultures. It is of special interest to psycholinguists because it is relatively consistent across individual speakers of a given language. Being an issue closely connected with the problems of foreign language acquisition, it very often brings to misunderstanding between native and non-native speakers. On the other hand, it proves the existence of the so-called interlanguage (approximate system, transitional competence, idiosyncratic dialect) which enables people to communicate with each other more or less sufficiently. Linguists even make jokes about FT by asking: "What is two tea to two two?" And the answer is: "It is a Chinese asking for two tea to room number twenty-two". Interlanguage, in reality, is an expression of the psychical processes involved in foreign language learning. Interlanguage is even thought to be a relatively independent system which results from a vague understanding of what the language one uses is. This brings to simplification, overgeneralization and transfer. In other words, here we deal with an individual set of rules and restrictions on how to use this or that language.

A detailed study of FT necessitates a consideration of a number of issues:

- The extent to which it occurs in native speaker/non-native speaker interactions.

- Grammatical input modifications.

- Ungrammatical input modifications.

- Interactional modifications.

- The discourse structure of FT.

- The functions served by it.

Overall, three functions of FT can be identified: it promotes communication, it signals, implicitly or explicitly speaker's attitude towards their interlocutors and, finally, it teaches the target language implicitly. In languages where native speakers employ a 
copula in equational clauses in normal communication, they often omit it in talk directed at foreigners. Ferguson (1975) suggests that this is because the absence of copula is considered simpler than its presence. The omission of copula is a clear example of ungrammatical FT. Ungrammaticality is evident in three ways:

1. Omission of grammatical functors such as copula, articles, conjunctions, subject pronouns, and inflectional morphology.

2. Expansion, as when you is inserted before an imperative verb (eg., You give me money.).

3. Replacement/rearrangement, as when post-verbal negation is replaced by preverbal negation in English FT (eg., No want play.).

Frequently utterances manifest all the three types. As Ferguson noted many of the features found in FT are also evident in pidgins.

It should be mentioned that there are striking similarities between ungrammatical FT and learner language. This should not be taken as evidence in favour of the matching hypothesis which claims that the source of learners' errors is ungrammatical FT, for, as both Long and Meisel (1988) noted, it may be useful to introduce ungrammatical forms of the kind they observe in learner language into their speech as part of the process of accommodating to their addressee.

A number of factors appear to induce ungrammatical FT. Long suggested the following four factors to be included in the list:

1. The learner's level of proficiency in L2 ungrammatical FT is more likely when the learner's proficiency is low.

2. The status of the native speaker ungrammatical FT is more likely when the native speaker is or thinks he or she is of higher status.

3. The native speaker has prior experience of using FT but only of the limited kind used to address non-native speakers of low proficiency.

4. The extent to which the conversation is spontaneous.

However, ungrammatical FT can occur both with interlocutors who are familiar and with strangers, suggesting that factors other than those mentioned are at work. Scholars are inclined to think that it is not yet possible to identify the exact conditions that will result in ungrammatical FT, perhaps because native speakers vary both culturally and individually in the kind of FT they prefer to use.

One thing is clear: ungrammatical FT is highly marked. In many situations it does not occur, suggesting that it constitutes a particular discourse type. Arthur et. al. (1980) recorded sixty telephone conversations between adult non-native speakers of English and airline ticket agents and reported no instance of ungrammatical input modifications. Studies of teachet talk (Hakansson 1986) also, not surprisingly, report absence of ungrammatical modifications, although other studies (Hatch, Shapira and WagnerGough 1978) did find instances in the language that teachers use to organize and manage classroom activities.

Grammatical modifications are the norm in most classrooms and, not surprisingly, in the modified texts of the kind found in graded readers. Grammatical FT is characterized by modifications reflecting both simplification and elaboration. But how do native 
speakers manage to adjust the level of their FT to suit the level of non-native speakers of the language? Most adjustments are geared to simplifying utterances to make them easier to process or to clarify what has been said by either the native speaker or the nonnative speaker (Hatch 1998). The author characterized the second function in terms of the special kind of affective bond that FT can create between the native speaker and nonnative speaker. In fact FT can reflect either downward divergence, such as when a native speaker deliberately employs ungrammatical forms with a competent non-native speaker to signal lack of respect. Or downward convergence such as when a native speaker approximates the inter-language forms used by non-native speakers as a way of signalling solidarity. This double function of FT may help to explain why ungrammatical FT can occur between non-familiar interlocutors in service or workplace encounters and between familiar interlocutors in ordinary conversation. The third function is only implicit because native speakers do not usually have any pedagogic intent, although Naro in a response to Hatch argued that FT can occur with an explicit teaching function (with the intention of helping a learner to learn).

When teaching the target language implicitly, FT is only implicit because native speakers do not usually have any pedagogic intent, although it can be argued that FT can occur with an explicit teaching function, for example, with the intention of helping a learner learn.

In English, FT is characterized phonologically by slower speech rate, greater pausing, greater segmentation of words, increased stress marking, more careful articulation and reduced assimilation. Lexis is usually simplified, relying on high-frequency items and avoiding idiom and slang. Syntax uses a limited range of basic structures and sometimes omits functions and inflections. It may employ syntactic forms which are incorrect (you no like?) There is a preference for transparent forms; full rather than contracted, for shorter utterances and for co-ordination rather than subordination. The standard SVO word order is adhered to quite strictly, though there may be some fronting of the current topic of conversation. FT is also characterized by a low level of information per sentence and by a high level of redundancy, including repetition and rephrasing.

It has already been mentioned that any of the formal characteristics of FT are very similar to those found in other simplified registers, such as learner language, caretaker talk. This suggests that it reflects universal processes of simplification of knowledge that plays an important role in speakers' linguistic competence which constitutes part of a speaker's linguistic competence. Still, there are also some differences, however, particularly when the non-native speakers are adults.

The main functional intent of caretaker talk is that of directing the child's behavior, that of FT is exchange of information. It should be noted, however, that when FT is addressed to young children, it appears to resemble caretaker talk fairly closely. So we may assume that the crucial factor, therefore, may be age.

Some differences are found between simplification registered in FT and that is observed in learner language. Whereas some scholars manifest restrictive simplification, for example, the use of an infinitive in place of inflected verb-forms, only learner language manifests elaborative simplification (the use of novel verb forms through such 
processes as overgeneralization). Restrictive simplification in both registers serves the purpose of achieving an optimal result in communication, but elaborative simplification occurs when learners are trying to complexify their inter-language system.

Interlanguage Talk (ILT) consists of the language that learners receive as input when addressed by other learners. A key issue is the extent to which ILT provides learners with adequate access to the grammatical properties of the target language. Not surprisingly, ILT has been found to be less grammatical than FT ot teacher talk in a detailed study of the ILT produced by intermediate and advanced L2 learners.

Native speakers come to be able to adjust the level of their FT to suit the level of individual learners in three main ways:

- Regression, when native speakers move back through the stages of development that characterized their own acquisition of language until they find an appropriate level.

- Matching, when native speakers assess a learner's current interlanguage state and then imitate the forms they observe in it.

- Negotiation when native speakers simplify and clarify in accordance with the feedback they obtain from learners in communication with them.

Matching seems less likely as it is probably asking too much of learners' phonology, lexicon, syntax, and discourse with sufficient accuracy to adjust their own language output. Thus, the most likely explanation is negotiation.

The need of going back to whatever has already been said for clarification reminds negotiation, the participants of which do not understand each others' aims, but still long for an agreement. This would better be called "negotiation of meaning" or "word meaning", more specifically.

Thus, communication in general and communication in a foreign language presupposes much consideration on the part of the interlocutor or language bearer. Still, efficient communication, especially in a foreign language is a skill which can be learnt. It is never late to do so, even if you are afraid, you are not sure or you do not know where it will bring you. We need to master communicative skills to feel comfortable, command more attention in the society and, after all, to promote efficient intercultural communication.

\section{References:}

1. Hakansson, G. (1986) Quantitative Studies of Teacher Talk. // Learning Teaching and Communication in the Foreign Language Classroom. / Ed. by G. Kasper. Aarhus: Aarhus University Press.

2. Hatch, E.; Shapira and J.Wagner-Gough (1983) Simplified Input and Second Language Acquistion. // Pidginization and Creolization as Language Acquisition. / Ed. by R. Andersen. Rowley, Mass.: Newbury House.

3. Scovel, T. (2001) Learning New Languages: A Guide to Second Language Acquisition. Bostone: Heinle and Heinle.

4. Ferguson, C. (1975) Towards a Characterization of English Foreigner Talk. // Anthropological Linguistics. Indiana: IUP. 
5. Long, M. (1988) Instructed Interlanguage Development. // Issues in Second Language Acquisition: Multiple Perspectives. / Ed. by L. Beebe. New-York: Newbury House.

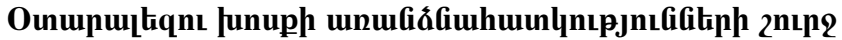

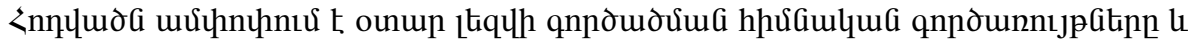

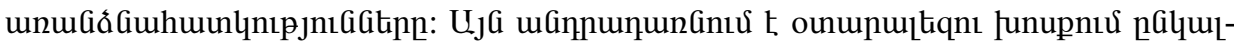

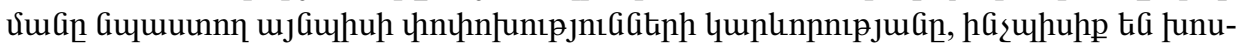

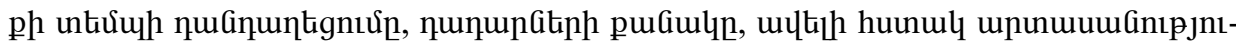

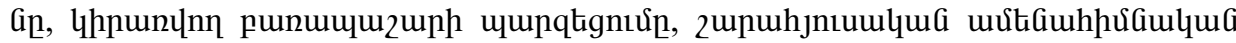

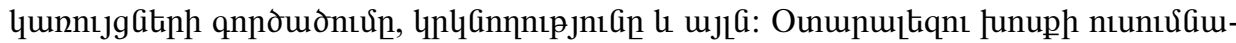

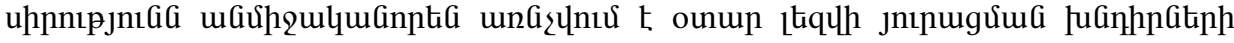

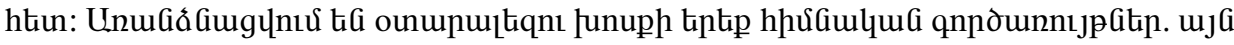

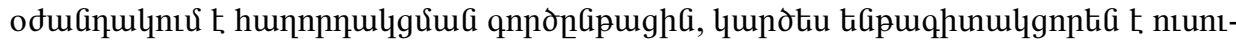

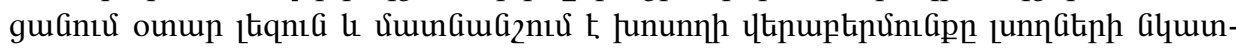
umun: 